\title{
LAPAROSCOPIC MYOMECTOMY
}

\author{
RADU CHICEA ${ }^{1}$, ANCA LUCIA CHICEA ${ }^{2}$, PAULA NIȚA $\breve{~}^{3}$ \\ 1,2,3 “Lucian Blaga” University of Sibiu, ${ }^{1,3}$ Sibiu County Emergency Clinical Hospital
}

Keywords: laparoscopy, Abstract: Pelvic masses are commonly diagnosed following clinical examination. These may be myomectomy, complication, infertility

\begin{abstract}
located in the genital organs or may interest other pelvic and abdominal organs. The pathology of the pelvic masses varies with age. The postmenopausal period is most commonly associated with malignant pathology while reproductive age is associated with benign pathology. The purpose of this paper is to present the experience of the Obstetrics and Gynaecology Clinic of the Sibiu County Clinical Emergency Hospital in laparoscopic myomectomy. We evaluated the patients admitted to the Obstetrics and Gynaecology Clinic of the Emergency County Clinical Hospital in Sibiu who underwent a laparoscopic myomectomy between 1.01.2015 - 06.06.2019. During this time, 14 laparoscopic myomectomies were performed in our clinic. Patients ranged in age from 29 to 57 years.
\end{abstract}

\section{INTRODUCTION}

Pelvic masses are commonly diagnosed following clinical examination. These may be located in the genital organs or may interest other pelvic and abdominal organs. The pathology of the pelvic masses varies with age. The postmenopausal period is most commonly associated with malignant pathology while reproductive age is associated with benign pathology.(1)

Uterine fibroids are a major health problem. These can affect patients' quality of life as well as reproductive function. Fibroids are benign tumours that originate in the myometrium. Their increase is dependent on the hormonal variations of estrogen and progesterone. Uterine fibroids have a low incidence in the period of pre-puberty and puberty. These increase in size at reproductive age and regress during the menopause. Often these are asymptomatic, but their number, size and location can cause symptoms such as menorrhagia, dysmenorrhea, pelvic discomfort and pain. $(2,3,4,5,6,7,8)$

Studies in the literature have shown that uterine fibroids have an increased incidence among African-American women. $(9,10,11,12,13,14,15)$

A Weiss study that included 3302 Caucasian and African-American women between the ages of 42 and 52 shows an increased incidence of leiomyomas among African-American women. Also, from the same study, it was found that African American women present more frequently with symptoms associated with uterine leiomyomas than Caucasian women. $(9,16)$ It is estimated that the incidence of leiomyomas is 3-4 times higher among African-American women.(9,17) Also, another study in the literature shows an increased rate of ultrasound diagnosed leiomyomas among African-American women compared to white women.(18)

Afro-American women are diagnosed with leiomyomas from an early age, which is associated with the early onset of symptomatology, most often having different responses to drug treatment in leiomyomas compared to white women.(19) African-American women have an increased rate of hospitalization due to complications from leiomyomas, as well as an increased prevalence of surgical treatment of this condition, represented by myomectomy and hysterectomy.(10,20,21)

Although the increased prevalence of leiomyomas has been known for decades among African-American women, biological or genetic studies in the literature are poor.

A study conducted in 2013 by Bird et al shows that the presence of leiomyomas is associated with low levels of vitamin D. In the same study, it was found that African American women had lower levels of vitamin D compared to white females.(22) One of the reasons why genetic studies related to the increased incidence of fibroids among African-American women are limited is that they have occurred in countries such as Japan and Finland where the African-American population is low. Another reason is that the African-American population is reluctant to enrol in these studies.(10)

Depending on their location, uterine fibroids may be submucosal, intramural and subserous.

The European Society for Gynaecological Endoscopy classifies leiomyomas in 3 degrees depending on the involvement of the myometer. Grade 0 - the fibroid is located entirely in the endometrial cavity; grade I - less than $50 \%$ is in the myometer; Grade II - more than $50 \%$ is in the myometer. Grade III - 100\% intramural with endometrial contact, Grade IV - $100 \%$ intramural, Grade V - sub serous and $>50 \%$ intramural, Grade VI - sub serous and $<50 \%$ intramural, Grade VII - sub serous pediculate.(1) There are more options in the treatment of uterine leiomyomas, some of them can be treated conservative or surgically depending of the symptoms and the women's desire to preserve their reproductive or menstrual function.

Therapeutic options for uterine fibroids include uterine artery embolization, hysteroscopic resection, classical or laparoscopic myomectomy and hysterectomy.(1) Although laparoscopic myomectomy is a more laborious intervention and

${ }^{1}$ Corresponding author: Radu Chicea, B-dul Corneliu Coposu, Nr. 2-4, Sibiu, România, E-mail: radu.chicea@gmail.com, Phone: +40269 215050 Article received on 20.03.2019 and accepted for publication on 02.06.2020 


\section{CLINICAL ASPECTS}

perceived by many surgeons as difficult, it presents several advantages such as decreased hospitalization, decreased administration of pain therapy in the postoperative period, rapid socioeconomic reintegration, low postoperative morbidity. Also, some studies in the literature show that there is no difference in reproductive capacity after laparoscopic myomectomy or myomectomy performed by minilaparotomy.(1,23,24,25)

Laparoscopic myomectomy is reserved for intramural and subserous fibroids. This is difficult to achieve on large uterus with multiple intramural leiomyomas that are difficult to identify as well as large leiomyomas that can be associated with increased operative time and increased bleeding. It is important to note that the laparoscopic myomectomy approach depends primarily on the surgeon's experience.(3) Cases of uterine rupture after laparoscopic myomectomy have been reported in the literature. These data highlight the importance of proper restoration of the integrity of the uterine wall. $(1,26,27,28)$

\section{AIM}

The aim of this paper is to present the experience of the Obstetrics and Gynaecology Clinic of the Sibiu County Clinical Emergency Hospital in laparoscopic myomectomy.

\section{MATERIALS AND METHODS}

We evaluated the patients admitted to the Obstetrics and Gynaecology Clinic of the Emergency County Clinical Hospital in Sibiu who underwent a laparoscopic myomectomy between 1.01.2015 - 06.06.2019. Patient data were obtained from the database of the department and the medical records of patients. The names of the patients were obtained from the departmental database using the type of surgery they underwent as a selection criterion. Age was not a criterion in the selection of patients.

For each patient medical records data considered were: age, symptoms, infertility history, GnRH antagonists and other hormone therapy before surgery, previous surgical interventions, intraoperative aspect of the leiomyomas, the size of the leiomyomas, modality of leiomyomas removal from the peritoneum, diagnosis, associated pathology, intraoperative complications, duration of hospitalization, the number of abdominal incisions used for laparoscopic approach.

The intraoperative evaluation was performed by inspection and targeted the following aspects: the presence of other tumours of genital or pelvic origin, the presence of adhesions, the number of leiomyomas, their location and dimensions.

\section{RESULTS}

During the time considered in the study, 14 laparoscopic myomectomies were performed in our clinic. Patients ranged in age from 29 to 57 years. The age distribution of the patients is illustrated in table no. 1 .

Table no. 1. Age distribution of patients

\begin{tabular}{|l|l|l|l|l|l|l|}
\hline Age & $25-29$ & $30-34$ & $35-39$ & $40-44$ & $45-49$ & $>50$ \\
\hline $\begin{array}{l}\text { Nr. of } \\
\text { cases }\end{array}$ & 3 & 3 & 3 & 2 & 2 & 1 \\
\hline
\end{tabular}

Primary or secondary infertility was the indication for 3 cases. All 3 patients with infertility were evaluated laparoscopically for evaluation if the tube patency or for previously diagnosed hydro-salpinx. In the other 11 cases the symptoms for which the surgery was performed were pelvic pain and menorrhagia. Some of the patients have received treatment with $\mathrm{GnRH}$ agonists, progestins or ulipristal acetat, according to the surgeons' experience, before surgery. One patient had a previous surgery - a caesarean section. The indication of the myomectomy it presented in figure no. 1 .
Figure no. 1. The indication for myomectomy

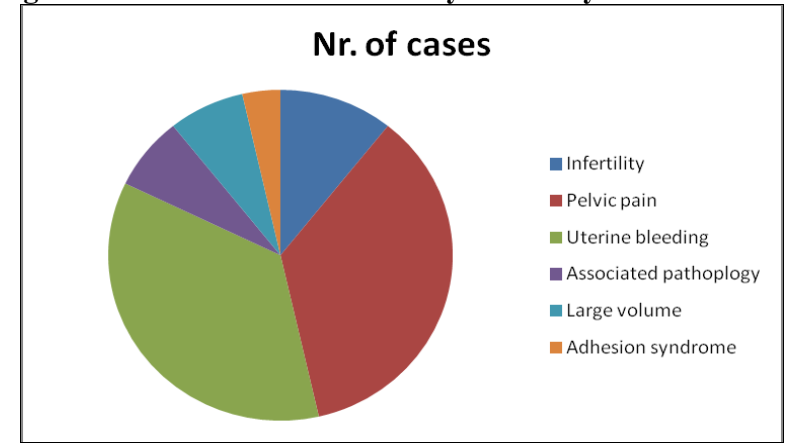

At the time of surgery, the diagnosis of uterine leiomyoma was established. The patients operated for infertility had a sub serous leiomyoma, grade V - grade VII according to the European Society for Gynaecological Endoscopy, located at the bottom of the uterus with dimensions between 2 and $2,5 \mathrm{~cm}$.

From the remaining 11 patients who underwent surgery for symptomatic uterine fibroids, one patient had 2 leiomyomas and another patient had 4 leiomyomas. Most patients had a single leiomyoma. The leiomyomas had dimensions between $0.5 \mathrm{~cm}$ and $8 \mathrm{~cm}$. The number of fibroids is presented in figure no. 2

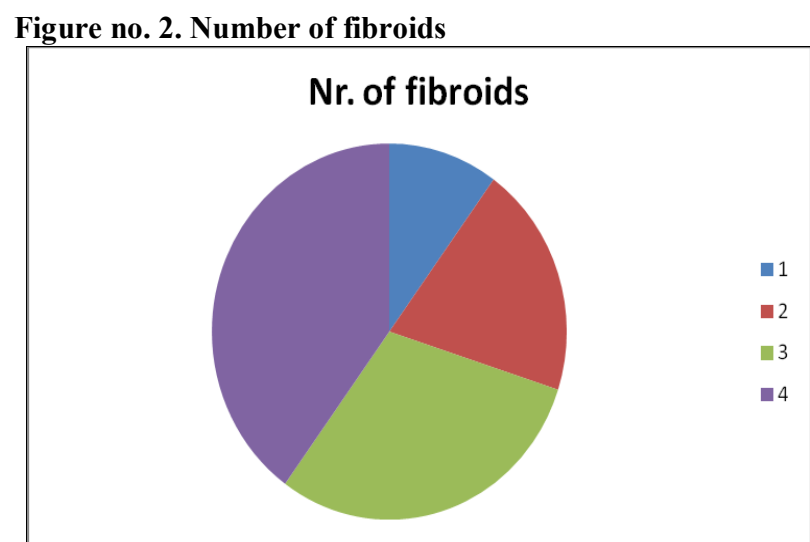

There were found different locations for the leiomyomas, 9 of the 14 patients had a subserous leiomyoma, and 5 had an intramural leiomyoma. In 7 of the 14 cases the leiomyomas were located at the level of the posterior uterine wall. In 4 cases the leiomyomas were located at the bottom of the uterus. In the other 3 cases the leiomyomas were located at the level of the anterior uterine wall. In two cases, adhesions were observed during the operation. One of the cases had a history of 2 births by Caesarean section. One of the patients besides the uterine leiomyoma also had an ovarian cyst with dimensions of approximately $6 \mathrm{~cm} / 7 \mathrm{~cm}$. Of the 14 cases, only 4 presented leiomyomas with a diameter greater than $4 \mathrm{~cm}$. In these cases the leiomyomas were extracted by a minilaparotomy incision with a length of about $4 \mathrm{~cm}$. Of the 5 patients who presented intramural leiomyoma, 3 had leiomyoma with a diameter over $4 \mathrm{~cm}$. In these cases, the integrity of the uterine wall was restored by a mini-laparotomy incision and open suture.

In all cases the laparoscopic approach was made through 3 incisions on the abdominal wall.

The average length of hospitalization was 5 days.

There were no complications during the surgery and immediately after the surgery.

Laparoscopic approach of uterine leiomyomas is a feasible therapeutic option where the local situation allows. 


\section{CLINICAL ASPECTS}

Usually it is difficult to approach intra-mural myomas (Grade III and IV because they are not evident on the surface of the uterus. The only myomas easy to remove are those seen on the surface of the uterus. The difficult decision is to consider if there are real benefits for woman health and reproductive capacity by removing asymptomatic myomas, discovered during laparoscopy for other reasons (especially for infertility). The benefit for fertility is usually achieved only after removing myomas larger than 5-6 centimetres otherwise the benefit is reduced.

The restoration of the integrity of the uterine wall after laparoscopic myomectomy is essential when the intervention is performed for patients who want to preserve fertility. Spontaneous or intrapartum uterine rupture has to be prevented by a solid, layer to layer suture to provide a good quality scar. It can be done laparoscopically or it can be done throw minilaparotomy incision in sight. This approach was chosen for all the patients willing to preserve fertility and to get a pregnancy in the future. This approach was chosen because of the cases presented in the literature have highlighted the possibility of uterine rupture in women who have obtained a pregnancy after laparoscopic suture of the uterus after myomectomy.(29,30,31) However, studies in the literature related to uterine rupture during pregnancy after myomectomy are contradictory. There have also been reported spontaneous uterine ruptures in the second trimester of pregnancy after classical myomectomy, not only after laparoscopic suture.(32)

Regarding the prevalence of achieving a pregnancy after myomectomy, it is shown in the literature that there is no noticeable difference in the prevalence of pregnancies after laparoscopic myomectomy or classical myomectomy.(33)

The size of the uterine myomas approached by laparoscopy is usually small because the most difficult part of the operation is to remove the myomas. The removal of the tissue can be done by a small, about 3-4 centimetres laparotomies or by different techniques of fragmentation of the myomas described in literature. Another option is peritoneal morcellation. It has to be done in an endobag, in order to prevent the spreading of the tumour cells in the peritoneum. At the beginning of the last decades a lot of rumour was recorded in the endoscopic surgery of the uterine myomas when peritoneal implants of mesenchymal malignant tumours were registered at short time after morcellation of uterine myomas, even if the histology of those tumours have been initially considered benign. In our days the myomas have to be removed either by mini - laparotomy or by morcellation in special designed endobags. $(34,35)$ In our study the small myomas were removed by morcellation in endobag with laparoscopic suture and by mini-laparotomy for patients investigated for infertility with open suture for a good quality scar.

Most laparoscopic myomectomies in our clinic have occurred in the last 3 years - 14 cases. The reason for an increase in laparoscopic myomectomy over the last 3 years is gaining experience in laparoscopic surgery, in laparoscopic sutures and achieving high power, bipolar morcellators in the recent years.

\section{CONCLUSIONS}

Laparoscopy is a feasible, minimal invasive surgical procedure to remove uterine leiomyomas.

In the last 3 years, there has been an increase in the number of laparoscopic myomectomies in our clinic, possible after improving of the surgical skills of the surgeons.

Important issues in laparoscopic surgery of the uterine leiomyomas is removal of the residual tissue which has to be done in the spirit of preventing the spreading of eventually malignant cells in the peritoneal cavity and the suture of the remaining defect of the uterus in order to achieve a good quality scar for preventing uterine rupture during pregnancy.

Laparoscopic myomectomy was not associated with complications during surgery or immediately after surgery

\section{REFERENCES}

1. Donnez J, Dolmans MM. Uterine fibroid management: from the present to the future. Hum Reprod Update. 2016;22(6):665-686. doi:10.1093/humupd/.

2. Al-Hendy A, Myers ER, Stewart E. Uterine Fibroids: Burden and Unmet Medical Need. Semin Reprod Med. 2017;35(6):473-480. doi:10.1055/s-0037-1607264.

3. Laughlin SK, Stewart EA. Uterine leiomyomas: individualizing the approach to a heterogeneous condition. Obstet Gynecol. 2011;117(2 Pt 1):396-403. doi:10.1097/AOG.0b013e31820780e3.

4. Stewart, EA, Cookson, CL, Gandolfo, RA, Schulze-Rath, R. Epidemiology of uterine fibroids: a systematic review. BJOG. 2017;124:1501-1512.

5. Buttram VC Jr, Reiter RC. Uterine leiomyomata: etiology, symptomatology, and management. Fertil Steril. 1981;36:433-45.

6. Khan AT, Shehmar M, Gupta JK. Uterine fibroids: current perspectives. Int J Womens Health. 2014;6:95-114

7. Zimmermann A, Bernuit D, Gerlinger C, Schaefers M, Geppert K. Prevalence, symptoms and management of uterine fibroids: an international internet-based survey of 21,746 women. BMC Womens Health. 2012;12:6.

8. Lippman SA, Warner M, Samuels S, Olive D, Vercellini P, Eskenazi B. Uterine fibroids and gynecologic pain symptoms in a population-based study. Fertil Steril. 2003;80:1488-94.

9. Sabry M, Al-Hendy A. Medical treatment of uterine leiomyoma. Reprod Sci. 2012;19(4):339-353. doi:10.1177/1933719111432867.

10. Eltoukhi HM, Modi MN, Weston M, Armstrong AY, Stewart EA. The health disparities of uterine fibroid tumors for African American women: a public health issue. Am J $\begin{array}{lll}\text { Obstet } & \text { Gynecol. 2014;210(3):194-199. }\end{array}$ doi:10.1016/j.ajog.2013.08.008.

11. Stewart EA, Nicholson WK, Bradley L, Borah BJ. The burden of uterine fibroids for African-American women: results of a national survey. J Womens Health (Larchmt). 2013;22(10):807-816. doi:10.1089/jwh.2013.4334.

12. Giri A, Edwards TL, Hartmann KE, et al. African genetic ancestry interacts with body mass index to modify risk for uterine fibroids. PLoS Genet. 2017;13(7):e1006871. Published 2017 Jul 17. doi:10.1371/journal.pgen.1006871.

13. Sengoba KS, Ghant MS, Okeigwe I, Mendoza G, Marsh EE. Racial/Ethnic Differences in Women's Experiences with Symptomatic Uterine Fibroids: a Qualitative Assessment. J Racial Ethn Health Disparities. 2017;4(2):178-183. doi:10.1007/s40615-016-0216-1.

14. Bray MJ, Wellons MF, Jones SH, Torstenson ES, Edwards TL, Velez Edwards DR. Transethnic and race-stratified genome-wide association study of fibroid characteristics in African American and European American women. Fertil Steril. doi:10.1016/j.fertnstert.2018.04.035 2018;110(4):737-745.e34

15. Ishikawa $H$, Reierstad S, Demura $M$, et al. High aromatase expression in uterine leiomyoma tissues of AfricanAmerican women. J Clin Endocrinol Metab 2009;94(5):1752-1756. doi:10.1210/jc.2008-2327.

16. Weiss G, Noorhasan D, Schott LL, Powell L, Randolph JF, Jr, Johnston JM. Racial differences in women who have a hysterectomy for benign conditions. Womens Health 


\section{CLINICAL ASPECTS}

Issues. 2009;19(3):202-210.

17. Amant F, Huys E, Geurts-Moespot A, et al. Ethnic variations in uterine leiomyoma biology are not caused by differences in myometrial estrogen receptor alpha levels. J Soc Gynecol Investig. 2003;10(2):105-109.

18. Day Baird D, Dunson DB, Hill MC, Cousins D, Schectman JM. High cumulative incidence of uterine leiomyoma in black and white women: ultrasound evidence. Am J Obstet Gynecol. 2003;188(1):100-107.

19. Jacoby VL, Fujimoto VY, Giudice LC, Kuppermann M, Washington AE. Racial and ethnic disparities in benign gynecologic conditions and associated surgeries. Am J Obstet Gynecol. 2010 Jun;202(6):514-21. Epub 2010 Apr 28.

20. Wu JM, Wechter ME, Geller EJ, Nguyen TV, Visco AG. Hysterectomy rates in the United States, 2003. Obstet Gynecol. 2007 Nov; 110(5):1091-5.

21. Wechter ME, Stewart EA, Myers ER, Kho RM, Wu JM. Leiomyoma-related hospitalization and surgery: prevalence and predicted growth based on population trends. Am J Obstet Gynecol. 2011 Nov;205(5):492.e1-5. Epub 2011 Jul 20.

22. Baird DD, Hill MC, Schectman JM, Hollis BW. Vitamin D and the risk of uterine fibroids. Epidemiology. 2013 May;24(3):447-53.

23. Bhave Chittawar P, Franik S, Pouwer AW, Farquhar C. Minimally invasive surgical techniques versus open myomectomy for uterine fibroids. Cochrane Database Syst Rev 2014;10:CD004638.

24. Donnez J, Donnez O, Dolmans MM. With the advent of selective progesterone receptor modulators, what is the place of myoma surgery in current practice. Fertil Steril 2014. a;102:640-648.

25. Segars JH, Parrott EC, Nagel JD, Guo XC, Gao X, Birnbaum LS, Pinn VW, Dixon D. Proceedings from the third National Institutes of Health International Congress on advances in uterine leiomyoma research: comprehensive review, conference summary and future recommendations. Hum Reprod Update 2014;20:309-333.

26. Dubuisson JB, Fauconnier A, Babaki-Fard K, Chapron C. Laparoscopic myomectomy: a current view. Hum Reprod Update. 2000;6:588-594.

27. Parker WH, Einarsson J, Istre O, Dubuisson JB. Risk factors for uterine rupture after laparoscopic myomectomy. J Minim Invasive Gynecol. 2010;17:551-554.

28. Thomas RL, Winkler N, Carr BR, Doody KM, Doody KJ. Abdominal myomectomy-a safe procedure in an ambulatory setting. Fertil Steril. 2010;94:2277-2280.

29. Chao AS, Chang YL, Yang LY, et al. Laparoscopic uterine surgery as a risk factor for uterine rupture during pregnancy. PLoS One. 2018;13(5):e0197307. Published 2018 May 22. doi:10.1371/journal.pone.0197307.

30. Kim HS, Oh SY, Choi SJ, et al. Uterine rupture in pregnancies following myomectomy: A multicenter case series. Obstet Gynecol Sci. 2016;59(6):454-462. doi:10.5468/ogs.2016.59.6.454.

31. Pakniat H, Soofizadeh N, Khezri MB. Spontaneous uterine rupture after abdominal myomectomy at the gestational age of 20 weeks in pregnancy: A case report. Int J Reprod Biomed (Yazd). 2016;14(7):483-486.

32. Vimercati A, Del Vecchio V, Chincoli A, Malvasi A, Cicinelli E. Uterine Rupture after Laparoscopic Myomectomy in Two Cases: Real Complication or Malpractice? Case Rep Obstet Gynecol. 2017;2017:1404815. doi:10.1155/2017/1404815.

33. Desai P, Patel P. Fibroids, infertility and laparoscopic myomectomy. J Gynecol Endosc Surg. 2011;2(1):36-42. doi:10.4103/0974-1216.85280.
34. Graebe K, Soto AG, Valarezo V, Heller PB, Tchabo N, Tobias DH, Salamon C, Ramieri J, Craig Dise B, Slomovitz M. Incidental power morcellation of malignancy: A retrospective cohort study, Gynecologic Oncology. https://doi.org/10.1016/j.ygyno.2014.11.018 2015:136(2):274-277.

35. Seidman MA, Oduyebo T, Muto MG, Nucci MR, Quade BJ, David J, Sullivan DJ. Peritoneal Dissemination Complicating Morcellation of Uterine Mesenchymal Neoplasms, PLoS One. 2012;v.7(11) doi:10.1371/journal.pone.0050058. 